Journal of Current and Advance Medical Research

July 2018, Vol. 5, No. 2, pp. 49-54

http://www.banglajol.info/index.php/JCAMR

ISSN (Print) 2313-447X

ISSN (Online) 2413-323X

DOI: http://dx.doi.org/10.3329/jcamr.v5i2.37059

ORIGINAL ARTICLE

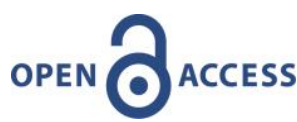

\title{
Comparison of Glasgow Outcome Scale (GOS) and Glasgow Coma Scale (GCS) between Surgical and Conservative Management of Spontaneous Supratentorial Intracerebral Hemorrhage Patients: A Randomized Control Trial
}

\author{
Mohammad Rafiqul Islam¹, Md. Shafiqul Kabir Khan², Md. Mahfuzur Rahman², Moajjam Hossain \\ Talukder ${ }^{4}$, Md. Rezaul Karim ${ }^{5}$, Abdus Salam ${ }^{6}$
}

\begin{abstract}
${ }^{1}$ Assistant Professor, Department of Neurosurgery, National Institute of Neurosciences \& Hospital, Dhaka, Bangladesh; ${ }^{2}$ Associate Professor, Department of Neurosurgery, Dhaka Medical College, , Dhaka, Bangladesh; ${ }^{3}$ Assistant Professor, Department of Neurotrauma, National Institute of Neurosciences \& Hospital, Dhaka, Bangladesh; ${ }^{4}$ Assistant Professor, Department of Neurotrauma, National Institute of Neurosciences \& Hospital, Dhaka, Bangladesh; ${ }^{5}$ Medical Officer, Intensive Care Unit, Pro Active Medical College and Hospital, Dhaka, Bangladesh; ${ }^{6}$ Associate Professor, Department of Neurotrauma, National Institute of Neurosciences \& Hospital, Dhaka, Bangladesh
\end{abstract}

[Received on: 2 January 2018; Reviewed on: 30 March 2018; Accepted on: 19 May 2018; Published on: 1 July 2018]

\section{Abstract}

Background: Glasgow outcome scale (GOS) and Glasgow Coma Scale (GCS) were the important parameter for the proper management of spontaneous supratentorial intracerebral hemorrhage patients. Objective: The purpose of the present study was to compare the GOS and GCS between surgical and conservative management of spontaneous supratentorial intracerebral hemorrhage patients. Methodology: This randomized control trial was conducted in the Department of Neurosurgery at Dhaka Medical College and Hospital from January 2010 to October 2011 for a period of one year and ten months. All hypertensive patients with spontaneous supratentorial intracerebral hemorrhage who were admitted within 48 hours of stroke in Neurosurgery Department during the study period were considered as a study population. Patients underwent surgery was considered as group I and patients those who did not give the consent for operation were treated conservatively was considered as group II. Result: A total of 31 patients were enrolled in this study of which 14 patients underwent surgical evacuation and 17 patients were selected for conservative therapy. Significant positive correlation was found between the GCS score on admission and GOS at 30 days follow-up in surgery group $(r=0.649 ; \mathrm{p}<0.05)$. But a positive significant correlation ( $\mathrm{r}=0.613 ; \mathrm{P}=0.020)$ was between GCS follow up with GCS on admission in surgery patients and $(\mathrm{r}=0.575 ; \mathrm{P}=0.016)$ in conservative group. Conclusion: In conclusion both GOS and GCS are essential during the management of surgical and conservative spontaneous supratentorial intracerebral hemorrhage patients. [Journal of Current and Advance Medical Research 2018;5(2):49-54]

Keywords: Haematoma Volume; Spontaneous; Supratentorial; Intracerebral Hemorrhage

Correspondence: Dr. Mohammad Rafiqul Islam, Assistant Professor, Department of Neurosurgery, National Institute of Neurosciences \& Hospital, Dhaka, Bangladesh; Email: drrafiqul_islam@yahoo.com; Cell no.: +8801717083088

Cite this article as: Islam MR, Md. Khan SK, Rahman MM, Talukder MH, Karim MR, Salam A. Comparison of Glasgow Outcome Scale (GOS) and Glasgow Coma Scale (GCS) between Surgical and Conservative Management of Spontaneous Supratentorial Intracerebral Hemorrhage Patients: A Randomized Control Trial. J Curr Adv Med Res 2018;5(2):49-54

Funding: This study has been performed without any funding from outside else.

Conflict of Interest: There was no conflict of interest to any of the authors.

Contributions to authors: Islam MR, Md. Khan SK, Rahman MM, Talukder MH, Karim MR, Salam A have contributed in protocol preparation, data collection, data analysis up to the report writing; Islam MR has written \& all the authors have revised the manuscript.

Copyright: (02018. Islam et al. Published by Journal of Current and Advance Medical Research. This article is published under the Creative Commons CC BY-NC License (https://creativecommons.org/licenses/by-nc/4.0/). This license permits use, distribution and reproduction in any medium, provided the original work is properly cited, and is not used for commercial purposes. 


\section{Introduction}

The high rate of morbidity and mortality has prompted investigations for new medical and surgical therapies for $\mathrm{ICH}^{1}$. According to World Health Organization (WHO) stroke may be defined as rapidly developing clinical signs of focal disturbance of cerebral function, lasting more than 24 hours or leading to death with no apparent cause other than that of vascular origin ${ }^{2}$. There are two main types of stroke. These are ischemic stroke $(85 \%)$ and hemorrhagic stroke $(15 \%)$; although hemorrhagic stroke accounts for only 10 to $15 \%$ of first ever stroke, with a 30 day mortality rate of $35 \%$ to $52 \%$; half of the deaths occur in the first 2 days $^{3}$.

Primary ICH is more common than secondary, accounting for 78 to $88 \%$ of cases, originates from the spontaneous rupture of small vessels damaged by chronic hypertension or amyloid angiopathy ${ }^{4}$. Secondary ICH occurs in a minority of patients in association with vascular abnormalities, such as arteriovenous malformation and aneurysms, tumors or impaired coagulation ${ }^{5}$.Uncontrolled hypertension is the most common factor contributing to spontaneous ICH and may explain the greater incidence of ICH in the black and Japanese populations. Epidemiologically, 70 to $90 \%$ of these hemorrhages are associated with hypertension ${ }^{6}$.

The classic presentation of ICH is the sudden onset of a focal neurological deficit that progresses over minutes to hours with accompanying headache, nausea, vomiting, decreased consciousness and elevated blood pressure. The Glasgow coma scale (GCS) score is often used to gauge the severity of ICH. GCS less than 8 carries a very poor prognosis ${ }^{7}$. Initial Glasgow coma scale score 6 to 12 in combination with volume of intracerebral hemorrhage is a powerful ${ }^{8}$ and easy to use predictor of 30 days mortality and morbidity in patients with spontaneous intracerebral hemorrhage ${ }^{5}$. In addition, location of hemorrhage, ventricular extension, hydrocephalus, pulse pressure, focal neurological deficits, and patient's age have to a varying extent, been of prognostic value ${ }^{9}$. Therefore the purpose of the present study was to compare the Glasgow outcome scale (GOS) and Glasgow coma scale (GCS) between surgical and conservative management of spontaneous supratentorial intracerebral hemorrhage patients.

\section{Methodology}

This was a single centred, parallel pragmatic randomized control trial which was conducted in the Department of Neurosurgery at Dhaka Medical College and Hospital from January 2010 to October 2011 for a period of one year and ten months. All hypertensive patients with spontaneous supratentorial intracerebral hemorrhage who were admitted within 48 hours of stroke in Neurosurgery Department during the study period were considered as a study population. The study population was divided into two groups designated as group I who were treated with surgical management and group II who were treated conservatively. Patients who didn't give consent for operation were selected for conservative therapy. Prior to commencement of this study, the research protocol was approved by ethical committee. The inclusion criteria of study population were patient admitted within 48 hours of ictus, CT-scan evidence of spontaneous supratentorial ICH, only lobar hematoma was included in this study, hematoma volume more than $30 \mathrm{ml}$ in CT-scan, hematoma causing mass effect like midline shift, GCS score 6 to 12 , age 40 to 70 years and only hypertensive cases were included in this study. The exclusion criteria of study population were patient after 48 hours of ictus, ICH other than spontaneous, posterior fossa (cerebellum) and deep seated (thalamus, putamen) hematoma, hematoma with ventricular extension, GCS score $<6$ and $>12$, patient with co morbid disease as diabetes, ischemic heart disease, COPD and patient taking any anticoagulant (as warfarin) and drugs that inhibit platelet aggregation (as aspirin). This study was done on admitted patients with a brain CT scan confirmed spontaneous supratentorial ICH fulfilling all selection criteria. All these patients were evaluated on the basis of detailed history and clinical examination. Clinical evaluation of the conscious level by Glasgow Coma Score (GCS $)^{10}$ was performed at the time of admission and seven days after treatment ${ }^{11}$. Glasgow Outcome Scale (GOS) was recorded one month after treatment ${ }^{12}$. The baseline volume of ICH was measured according to a bedside method of measuring CT $\mathrm{ICH}$ volume. The Broderick's formula $(\mathrm{AxBxC}) / 2$ was used ${ }^{5}$. Laboratory testing were performed like complete blood count, blood sugar level and $\mathrm{ECG}^{13}$. After giving the consent, patients selected for surgical treatment were taken to the operating room as soon as possible. All surgical cases underwent either decompressive craniotomy or craniectomy under general anesthesia. Medical treatment included osmotherapy, blood pressure control, seizure prophylaxis, deep venous thrombosis prophylaxis, intravenous fluids, $\mathrm{H} 2$ blockers and early nutritional support ${ }^{13}$. Among them 14 patients were operated and 17 patients those did not give consent for operation were treated conservatively, 
then continuously followed up by observing the GCS score at $7^{\text {th }}$ day and 30 days Glasgow outcome scale (GOS). A check list was prepared by the researcher considering the variables such as age, volume of haematoma, GCS and GOS. The check list was tested first in the department of Neurosurgery of Dhaka Medical College and Hospital and then finalized. The data was collected by the researcher himself. On admission, detailed history from the attendants was taken. General and neurological examination of patients was done. Findings of CT scan were recorded carefully. GCS and GOS were also recorded. Data was collected and edited manually. A master sheet was prepared and data was analyzed by SPSS (Statistical package for social science). Unpaired t test, paired t test, correlation and Chi square $\left(\chi^{2}\right)$ test were performed. The level of significance considered $p$ value $<0.05$. The summarized data was then presented in tabulated form.

\section{Results}

A total of 60 patients having stroke within 48 hours with spontaneous supratentorial ICH were selected. Out of these 29 patients were not included in the study due to unable to fulfill the selection criteria. Fourteen (14) patients underwent surgical evacuation while seventeen (17) patients those who didn't give consent for operation were selected for conservative therapy. Therefore a total of 31 patients were enrolled in this study.

The mean \pm SD age were $53.29 \pm 6.92$ years and $52.47 \pm 7.51$ years in surgery and conservative patients respectively. Half of the surgery patients were in between 40 to 50 years of age group. Besides, in conservative patients maximum $7(41.2 \%)$ number was found in both 40 to 50 years and 51 to 60 years. Mean age difference was not statistically significant $(\mathrm{p}>0.05)$ (Table 1$)$.
Table 1: Age distribution of the study patients $(\mathbf{n}=31)$.

\begin{tabular}{|c|c|c|c|}
\hline Age Group & Gr I & Gr II & $\begin{array}{c}\mathbf{P} \\
\text { value }\end{array}$ \\
\hline 40 to 50 Years & $7(50.0 \%)$ & $7(41.2 \%)$ & \multirow{6}{*}{$0.758^{\mathrm{ns}}$} \\
\hline 51 to 60 Years & $5(35.7 \%)$ & $7(41.2 \%)$ & \\
\hline$>60$ Years & $2(14.3 \%)$ & $3(17.6 \%)$ & \\
\hline Total & $14(100.0 \%)$ & $17(100.0 \%)$ & \\
\hline Mean \pm SD & $53.29 \pm 6.92$ & $52.47 \pm 7.51$ & \\
\hline $\begin{array}{l}\text { Range (min- } \\
\operatorname{max)}\end{array}$ & 45 to 65 & 40 to 65 & \\
\hline
\end{tabular}

ns $=$ not significant; $P$ value reached from unpaired $\mathrm{t}$-test; $\mathrm{Gr}=$ group

Mean GCS on admission was $8.79 \pm 1.63$ and $9 \pm 2$ in surgery and conservative patients respectively. No significant ( $>0.05)$ difference was found. Moreover, mean GCS on follow-up was $10.43 \pm 3.03$ and $7.76 \pm 3.15$ in surgery and conservative patients respectively.

Table 2: Mean distribution of the study patients according to GCS on admission and GCS at $7^{\text {th }}$ day follow-up $($ Mean \pm SD $)$

\begin{tabular}{|l|c|c|c|}
\hline Parameters & Gr I & Gr II & ${ }^{a} \boldsymbol{p}$ value \\
\hline GCS on admission & $8.79 \pm 1.63$ & $9.0 \pm 2$ & $0.749^{\text {ns }}$ \\
\hline Range (min-max) & $6-12$ & $6-12$ & \\
\hline GCS on follow-up & $10.43 \pm 3.03$ & $7.76 \pm 3.15$ & $0.024^{\mathrm{s}}$ \\
\hline Range (min-max) & 4 to 14 & 4 to 12 & \\
\hline${ }^{\text {bP value }}$ & $0.024^{\mathrm{s}}$ & $0.067^{\text {ns }}$ & \\
\hline
\end{tabular}

$\mathrm{s}=$ significant, $\mathrm{ns}=$ not significant; ${ }^{\text {aP }} \mathrm{value}$ reached from unpaired $\mathrm{t}$-test; ${ }^{\mathrm{b} P}$ value reached from paired $\mathrm{t}$-test

Significant $(\mathrm{p}<0.05)$ difference was found. GCS on admission and GCS on follow-up means score difference was statistically significant $(\mathrm{p}<0.05)$ in surgery, but was not statistically significant $(\mathrm{p}>0.05)$ in conservative group (Table 2$)$.

Table 3: Correlation between GCS Score on admission and GOS at 30 days $(n=31)$

\begin{tabular}{|l|c|c|c|c|}
\hline \multirow{2}{*}{ GOS } & \multicolumn{2}{c|}{ Surgery $(\mathbf{n}=\mathbf{1 4})$} & \multicolumn{2}{c|}{ Conservative $(\mathbf{n}=\mathbf{1 7})$} \\
\hline & GCS Score on admission & \multicolumn{2}{c|}{ GCS Score on admission } \\
\hline Dead & $6-8$ & $9-12$ & $6-8$ & $9-12$ \\
\hline Severe disabled & $4(66.67 \%)$ & $2(25.0 \%)$ & $7(77.8 \%)$ & $3(37.5 \%)$ \\
\hline Moderate disabled & $1(16.67 \%)$ & $1(12.5 \%)$ & $1(11.1 \%)$ & $2(25.0 \%)$ \\
\hline Good recovery & $1(16.67 \%)$ & $1(12.5 \%)$ & $0(0.0 \%)$ & $1(12.5 \%)$ \\
\hline Total & $0(0.0 \%)$ & $4(50.0 \%)$ & $1(11.1 \%)$ & $2(25.0 \%)$ \\
\hline
\end{tabular}


Table 3 shows 6 patients had GCS score 6 to 8 on admission, among them 4(66.67\%) patients were dead. Besides 8 patients had GCS score 9 to 12 among them $2(25.0 \%)$ patients were dead and 4 $(50.0 \%)$ patients had good recovery. Significant positive correlation between the GCS score on admission and Glasgow outcome scale (GOS) at follow-up was found in surgery group ( $\mathrm{r}=0.649$; $\mathrm{p}<0.05)$. On the other hand 9 patients had GCS score 6 to 8 on admission, among them 7(77.8\%) patients were dead. Besides 8 patients had GCS score 9 to 12 among them 3(37.5\%) patients were dead and 2(25.0\%) patients had good recovery. Positive but not significant correlation between the GCS score on admission and Glasgow outcome scale (GOS) at follow-up was found in conservative group ( $\mathrm{r}=0.419 ; \mathrm{p}>0.05)$.

\section{Discussion}

This comparative study was carried out with an aim to compare the outcome of surgery in relation to conservative management of spontaneous supratentorial intracerebral hemorrhage. A total of 31 patients with spontaneous supratentorial $\mathrm{ICH}$, evaluated by brain $\mathrm{CT}$ scan were included in the study, in the Department of Neurosurgery of Dhaka Medical College and Hospital, Dhaka during January 2010 to October 2011. Fourteen patients underwent surgery was considered as group I and 17 patients those who did not give consent for operation were treated conservatively was considered as group II and subsequently followed up by monitoring the GCS $7^{\text {th }}$ day and GOS at 30 days.

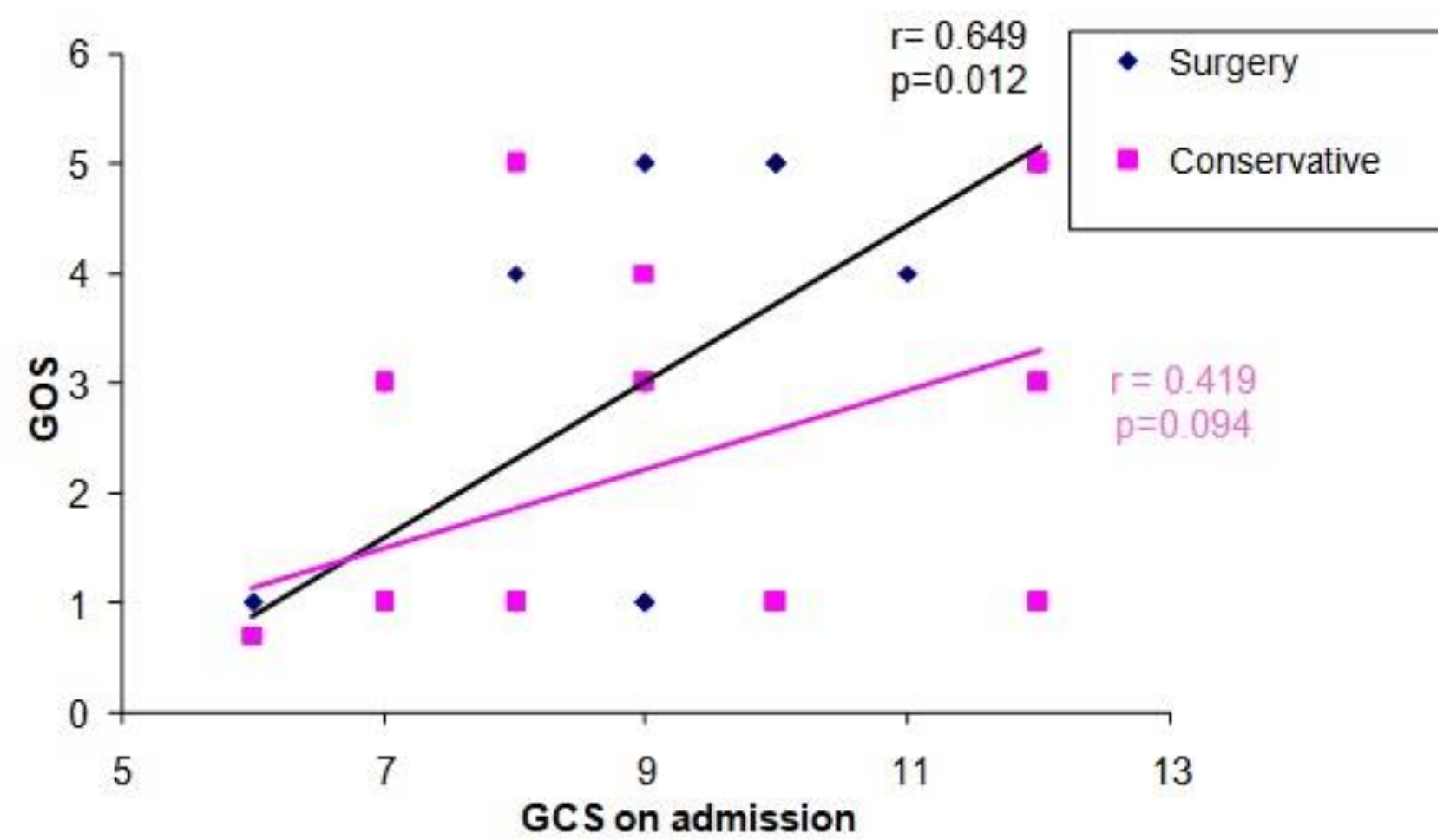

Figure I: Scatter diagram showing positive significant correlation $(\mathrm{r}=0.649 ; \mathrm{P}=0.012)$ between GOS with GCS on admission in surgery patients and positive but not significant correlation $(r=0.419 ; \mathrm{P}=0.094)$ between GOS with GCS on admission in conservative patients

In this present study it was observed that the mean \pm SD age was $53.29 \pm 6.92$ years and $52.47 \pm 7.51$ years in surgery and conservative group respectively, which was almost similar between two groups, no statistical significant $(\mathrm{p}>0.05)$ difference was observed. A half $(50.0 \%)$ of the surgery patients were in $5^{\text {th }}$ decade. Besides, in conservative group maximum $(41.2 \%)$ patients were found in $5^{\text {th }}$ and $6^{\text {th }}$ decade. Similarly, Mourad et $\mathrm{al}^{13}$ have observed the mean age of the patients having spontaneous supratentorial ICH was $56.65 \pm 11.47$ years in surgery group and $49.60 \pm 15.28$ years in conservative group and the difference was not statistically significant $(p>0.05)$, thus support the present study. Whereas in Bangladesh, Tarikul ${ }^{8}$ has shown mean age was 55.70 years and in Pakistan, Ahmed et $\mathrm{al}^{14}$ have shown the mean age was 58.8 years in patients having spontaneous intracerebral hemorrhage, which is comparable with the current study. 
In this current series it was observed that the mean GCS on admission was $8.79 \pm 1.63$ and $9 \pm 2$ in surgery and conservative group respectively, which was almost identical between two groups and no statistical significant $(p>0.05)$ difference was observed. Moreover, the mean GCS on follow-up at $7^{\text {th }}$ days was significantly $(\mathrm{p}<0.05)$ increased in surgery group but decline in conservative group however not significantly $(p>0.05)$ decreased, where the mean GCS on follow-up at $7^{\text {th }}$ days were $10.43 \pm 3.03$ and $7.76 \pm 3.15$ in surgery group and conservative group respectively. The mean GCS score was significantly $(\mathrm{p}<0.05)$ higher in surgery group with compared to conservative group. Comparing surgical treatment to the conservative treatment groups at baseline Mourad et $\mathrm{al}^{13}$ showed GCS was no statistically significant differences, which is closely support with the current study. Similarly, the investigators showed the mean GCS score was not statistically significant $(p>0.05)$ at final follow-up, but the GCS score was improved at final follow-up in both groups. In our country, Rahman ${ }^{11}$ showed the mean GCS on admission was $8.9 \pm 1.69$ in surgery group and $9.7 \pm 2.69$ in conservative group. Similarly, at $7^{\text {th }}$ day's followup, the mean GCS was significantly improved in both groups, which were $11.2 \pm 1.45$ in surgery group and 12.0 \pm 2.01 in conservative group, which is consistent with the present study.

According to GOS in relation to admission GCS in this study it was found that 6 patients had GCS score 6 to 8 on admissions, among them $4(66.67 \%)$ patients were dead. Besides 8 patients had GCS score 9 to 12 among them $2(25.0 \%)$ patients were dead and $4(50.0 \%)$ patients had good recovery. Significant positive correlation between the GCS score on admission and Glasgow outcome scale (GOS) at follow-up was found in surgery group $(\mathrm{r}=0.649 ; \mathrm{p}<0.05)$. This correlate the Tarikul ${ }^{8}$ study $(\mathrm{r}=0.576 ; \mathrm{p}<0.05)$, where investigator found $60 \%$ dead in GCS 6-8 and 60\% good recovery in GCS 912. Cho et $\mathrm{al}^{15}$ shown that patients with a GCS score of 9 to 12 surgical treatment had a lower mortality rate $(10.5 \%)$ than conservative treatment $(20 \%)$. Besides Mourad et $\mathrm{al}^{13}$ found negative but not signification correlation between baseline GCS and GOS. On the other hand 9 patients had GCS score 6 to 8 on admission, among them $7(77.8 \%)$ patients were dead. Besides 8 patients had GCS score 9 to 12 among them $3(37.5 \%)$ patients were dead and $2(25.0 \%)$ patients had good recovery. Positive but not significant correlation between the GCS score on admission and Glasgow outcome scale (GOS) at follow-up was found in conservative group $(\mathrm{r}=0.419 ; \mathrm{p}>0.05)$. It is evident that surgical outcome was better when baseline GCS was 9-12.
In this present study it was observed that a positive significant correlation between GCS on admission with GCS at $7^{\text {th }}$ day follow up both in surgery group $(\mathrm{r}=0.613 ; \mathrm{p}=0.020)$ and in conservative group $(\mathrm{r}=0.575 ; \mathrm{p}=0.016)$. This correlates with Mourad et $\mathrm{al}^{13}(\mathrm{r}=0.477 ; \mathrm{p}=0.034)$ and Morgenstern et $\mathrm{al}^{16}$. Whereas Tarikul ${ }^{8}$ also found significant correlation between GCS on admission with GCS at $30^{\text {th }}$ day follow up in surgery group $(\mathrm{r}=0.58, \mathrm{p}=0.001)$. Current study showed positive significant correlation $(r=0.649 ; p=0.012)$ between GOS with baseline GCS in surgery patients and positive but not significant correlation $(\mathrm{r}=0.419 ; \mathrm{p}=0.094)$ between GOS with baseline GCS in conservatively managed patients. This correlates with Mourad et $\mathrm{al}^{13}(\mathrm{r}=0.381 ; \mathrm{p}=0.024)$ in surgery group.

\section{Conclusion}

This study concludes that surgical evacuation of spontaneous supratentorial intracerebral hemorrhage has a benefit on outcome compared to conservative medical treatment. It may be only considered in hematoma $30-60 \mathrm{ml}$ with moderate impairment of conscious level (GCS 9-12). Thus the decision of whether or not to surgically evacuate supratentorial ICH should depend on a combination of hematoma size and initial GCS. This combination may be the best current predictor of benefit, outcome and mortality following surgical treatment. In the modern era of CT, good neuroanesthesia, intensive care and the operating microscope, surgery has a role in the treatment of spontaneous supratentorial intracerebral hemorrhage. Minimally invasive techniques like stereotactic and endoscopic procedures should be tried to compare with the outcome of conservative management. Further randomized control trials involving large number of study population involving several investigators at multicentres with longer follow ups should be done to assess proper management and outcome of patients of SICH.

\section{References}

1. Steiner T, Juttler E. American guidelines for the management of spontaneous intracerebral hemorrhage in adults: European perspective. Polskie Archiwum Medycyny Wewnetrznej. 2008;118(4):181-182

2. Hatano S. Experience from a multicentre stroke register: a preliminary report. Bulletin of the World Health Organization. 1976;54(5):541-53

3. Broderick J, Connolly S, Feldmann E, Hanley D, Kase C, Krieger D, Mayberg M, Morgenstern L, Ogilvy CS, Vespa P, Zuccarello M. American Heart Association, American Stroke Association. Guidelines for the management of intracerebral hemorrhage in adults: 2007 update. Stroke. 2007;38:2001-23 
4. Foulkes MA, Wolf PA, Price TR, Mohr JP, Hier DB. The Stroke Data Bank: design, methods, and baseline characteristics. Stroke. 1988;19(5):547-54

5. O'Donnell HC, Rosand J, Knudsen KA, Furie KL, Segal AZ, Chiu RI, Ikeda D, Greenberg SM. Apolipoprotein E genotype and the risk of recurrent lobar intracerebral hemorrhage. New England Journal of Medicine. 2000;342(4):240-5

6. Weiner HL, Cooper PR. The Management of Spontaneous Intracerebral Hemorrhage. Contemporary Neurosurgery. 1992;14(21):1-8

7. Abdulrauf SI, Furlan AJ, Awad I. Primary intracerebral hemorrhage and subarachnoid hemorrhage. Journal of Stroke and Cerebrovascular Diseases. 1999;8(3):146-50

8. Tarikul, I., 2011. Analysis of early outcome of surgery in spontaneous primary intracerebral haemorrahage in relation to preoperative Glasgow coma scale, MS (Neurosurgery Thesis), University of Dhaka.

9. Nilsson OG, Lindgren A, Brandt L, Säveland H. Prediction of death in patients with primary intracerebral hemorrhage: a prospective study of a defined population. Journal of neurosurgery. 2002;97(3):531-6

10. Teasdale G, Jennett B. Assessment of coma and impaired consciousness: a practical scale. The Lancet. 1974;304(7872):81-4

11. Rahman, A., 2008. Comparative study between outcomes of patients of supratentorial spontaneous intracerebral haematoma treated conservatively and surgically, MS (Neurosurgery Thesis), University of Chittagong.
12. Wilson JL, Pettigrew LE, Teasdale GM. Structured interviews for the Glasgow Outcome Scale and the extended Glasgow Outcome Scale: guidelines for their use. Journal of neurotrauma. 1998;15(8):573-85

13. Mourad HS, Enab AA, Abdelalim AM. Early outcome of Conservative versus Surgical Treatment of Spontaneous Supratentorial Intracerebral Hemorrhage. Egyptian Journal of Neurology, Psychiatry and Neurosurgery 2011;48:8592

14. Ahmed R, Shakir AH, Moizuddin SS, Haleem A, Ali S, Durrani K, Khan A, Baig S. Predictors of in-hospital mortality for intracerebral hemorrhage: a hospital-based study in Pakistani adults. Journal of Stroke and Cerebrovascular Diseases. 2001;10(3):122-7

15. Cho DY, Chen CC, Lee HC, Lee WY, Lin HL. Glasgow Coma Scale and hematoma volume as criteria for treatment of putaminal and thalamic intracerebral hemorrhage. Surgical neurology. 2008;70(6):628-33

16. Morgenstern LB, Hemphill JC, Anderson C, Becker K, Broderick JP, Connolly ES, Greenberg SM, Huang JN, Macdonald RL, Messé SR, Mitchell PH. Guidelines for the management of spontaneous intracerebral hemorrhage. A guideline for healthcare professionals from the American Heart Association/American Stroke Association. Stroke. 2010;41(9):2108- 29 